\title{
Electrosynthesis and Characterization of Adherent Poly (4-Amino-3 Methyl-1,2,4-Triazole-5-Thione) Films on B66 Bronze Electrode in Methanol
}

\author{
H. Benassaoui ${ }^{a, *}$, M. Damej ${ }^{a}$, E. Benassaoui ${ }^{a}$, A. Dermaj ${ }^{a}$, \\ H. Erramli ${ }^{a}$, D.Chebabe ${ }^{a, b}$, N. Hajjaji ${ }^{a}$ and A. Srhiri ${ }^{a}$ \\ ${ }^{a}$ Laboratory of Environmental Engineering and Biotechnology, ENSA, Ibn Zohr University, \\ P.O. Box 1136, 80000 Agadir, Morocco \\ ${ }^{b}$ Regional Centre for Education and Training, Souss Massa, Inzegane, Morocco
}

Received March 20, 2018; accepted February 23, 2019

\begin{abstract}
The electro-oxidation of 4-amino-3-methyl-1,2,4-triazole-5-thione (MTSNH) on a bronze substrate in an alkaline methanol solution produces a homogeneous polymer film. The formation kinetics of the film was investigated using cyclic voltammetry, chronoamperommetry and electrochemical impedance spectroscopy.

Cyclic voltammograms indicated that the polymer film (pMTSNH) was formed anodically between -350 and $350 \mathrm{mV} / \mathrm{SCE}$. During the second cycle, the oxidation peak of the monomer disappeared, indicating the formation of the insulating film. We have also shown that the monomer oxidation reaction is essentially irreversible and controlled by a diffusion process. The inhibition efficiency of this polymer was determined by potentiodynamic polarization and electrochemical impedance spectroscopy in a $3.5 \% \mathrm{NaCl}$ solution.
\end{abstract}

Keywords: cyclic voltammetry, chronoamperometry, B66 bronze alloy, corrosion, inhibition.

\section{Introduction}

Bronze artifacts are generally covered with green or blue colored corrosion products called patina, which not only enhance the good appearance of bronze, but also help to protect it. However, because of an increase in air pollution, bronze present in an urban environment suffers an acceleration of corrosion and alteration of its aspect. The use of an organic coating [1] is an adapted and convenient method to protect our cultural heritage.

Electrochemical polymerization is a simple and attractive approach for forming a polymer film onto the electrode surface [2-4]. The thickness of the film can be controlled, the functionality of the formed coating film can be selected through

\footnotetext{
*Corresponding author. E-mail address: h.benassaoui@gmail.com
} 
processing parameters (current density, scan rate, scan number, temperature, etc.), and uniform coatings can be achieved [5-7].

Organic coatings have been investigated through the evaluation of their barrier properties using electrochemical impedance spectroscopy [8-11].

The aim of this paper is to study the electropolymerization of 4-amino-3-methyl1,2,4-triazole-5-thione (MTSNH) in a medium of $\mathrm{KOH} 0.1 \mathrm{M}$ dissolved in pure methanol, and to discuss the results obtained in studying the inhibiting effect of the polymer film against $\mathrm{B} 66$ bronze corrosion in a $3.5 \% \mathrm{NaCl}$ solution.

\section{Experimental}

\section{Inhibitor}

4-amino-3-methyl-1,2,4-triazole-5-thione (MTSNH) was prepared in one step. It resulted of a simple solvolysis of thiocarbohydrazide in acetic acid [12]. The structure of this compound (Fig.1) was confirmed by NMR analysis.

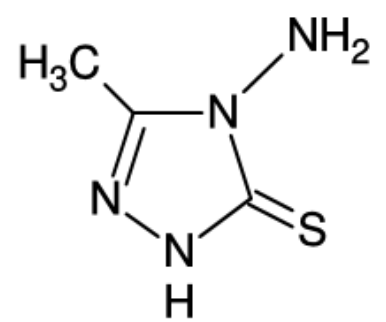

Figure 1. Molecular structure of MTSNH.

This product was characterized by ${ }^{1} \mathrm{H}$ NMR and ${ }^{13} \mathrm{C}$ NMR spectroscopy. The $1 \mathrm{H}$ NMR spectra of MTSNH indicated a singlet corresponding to the proton character of the methyl group which was observed at $\delta=2.22 \mathrm{ppm}$. The $\mathrm{NH}$ proton appeared as singlet at $\delta=13.38 \mathrm{ppm}$, presumably due to the existence of thiol-thione tautomerism, and a singlet was observed at $\delta=5.49 \mathrm{ppm}$, for $\mathrm{NH}_{2}$ groups.

The ${ }^{1} \mathrm{H}$ NMR spectrum of MTSNH was confirmed by the ${ }^{13} \mathrm{C}$ NMR spectrum performed for that derivative. The $\mathrm{CH}_{3}$ signal appeared at $10.84 \mathrm{ppm}$ and the $\mathrm{C}(3)$ and $\mathrm{C}(5)$ heterocyclic carbon resonated at $\delta=149.61 \mathrm{ppm}$ and $165.82 \mathrm{ppm}$, respectively.

\section{Electrolyte solution}

The aggressive solution of $3.5 \% \mathrm{NaCl}$ was prepared by dissolving $\mathrm{NaCl}$ (SigmaAldrich) in distilled water.

Table 1. Composition of bronze determined by EDX analysis.

\begin{tabular}{|l|c|c|c|c|c|}
\hline Element & Sn & Pb & Ni & Zn & Cu \\
\hline Phase I (Wt \%) & 5.12 & 0.59 & 0.39 & 0.79 & 93.11 \\
Phase II (Wt \%) & 21.29 & 1.69 & 0.38 & 0.29 & 76.35 \\
\hline
\end{tabular}




\section{Bronze samples}

The working electrode was commercial biphasic bronze. Its composition was confirmed by EDX analysis and is summarized in Table 1 [11].

\section{Electrochemical techniques}

Polarization measurements

Electrochemical experiments were carried out in a cell with a platinum counter electrode and a saturated calomel electrode (SCE) as reference electrode. The working electrode used in this study was a B66 bronze disk electrode $\left(0.78 \mathrm{~cm}^{2}\right)$. It was cut from bronze and was embedded in polytetrafluoroethylene (PTFE), so that the flat surface was the only one in the electrolyte. All experiments were carried out in methanol. Potassium hydroxide was used as a supporting $10^{-1} \mathrm{M}$ electrolyte. Before use, the surface of the specimen was polished with emery paper ranging from 600 to 2000 , rinsed in water, degreased with acetone and hotair dried.

The voltammograms, I-t transient curves and the electrochemical impedance measurements were performed using a potentiostat-galvanostat SP-200 "Bio Logic Science Instruments".

The inhibition efficiency (E \%) was calculated from potentiodynamic polarization curves using the following equation:

$$
E \%=\frac{i_{s}-i_{a}}{i_{s}} \times 100
$$

where $\mathrm{I}_{s}$ is the corrosion current density in the absence of the inhibitor and $\mathrm{I}_{a}$ is the corrosion current density in the presence of the inhibitor.

\section{Electrochemical impedance spectroscopy (EIS)}

The measurements of electrochemical impedance spectroscopy were realized at $25{ }^{\circ} \mathrm{C}$, with respect to the corrosion potential $\left(\mathrm{E}_{\mathrm{corr}}\right)$, over a frequency range of $100 \mathrm{kHz}$ to $10 \mathrm{mHz}$, with a signal amplitude perturbation of $1 \mathrm{mV} \mathrm{s}^{-1}$. Data were presented as Nyquist plots and analyzed by the EC-LAB software [13]. The inhibition efficiency at different concentrations of FBN was evaluated by the following equation:

$$
E \%=\frac{R_{p}{ }^{a}-R_{p}^{s}}{R_{p}{ }^{a}}
$$

where $\mathrm{R}_{p}{ }^{s}$ is the polarization resistance for the uninhibited solutions and $\mathrm{R}_{p}{ }^{a}$ is the polarization resistance for the inhibited solutions [14].

\section{Surface analysis}

The specimens used for surface morphology were characterized by scanning electron microscopy coupled with EDX elemental analysis. The microscope used in this study is a FEI (model quanta FEG 450). The EDX is flash 6130 model $\mathrm{X}$ (Bruker). 


\section{Results and discussion}

\section{Electrochemical properties of MTSNH}

Cyclic polarization

Cyclic voltammograms (CVs) of MTSNH at the B66 bronze electrode were performed at a concentration of $10^{-3} \mathrm{M}$ of MTSNH in a methanol solution with $10^{-1} \mathrm{M} \mathrm{KOH}$ as supporting electrolyte. The CVs were recorded for 10 successive cycles at a scan rate of $10 \mathrm{mV} / \mathrm{s}$, for a potential range from -0.350 to $0.350 \mathrm{~V}$, in the presence and absence of MTSNH.

The obtained voltammograms show only one peak around $\mathrm{E}=176 \mathrm{mV} / \mathrm{SCE}$. This peak may be assigned to the monomer/oxidation. In the absence of monomer, no peak was detected.

As show in Fig. 2, the value of the current density decreases when the number of cycles increases. This may be attributed to the polymer film formation onto the electrode surface, as proposed in a similar case [15].

After the second cycle, all electroactivity was lost, and no electrochemical response was observed at all, and the oxidation peak of the monomer disappeared, indicating the formation of the insulating film.

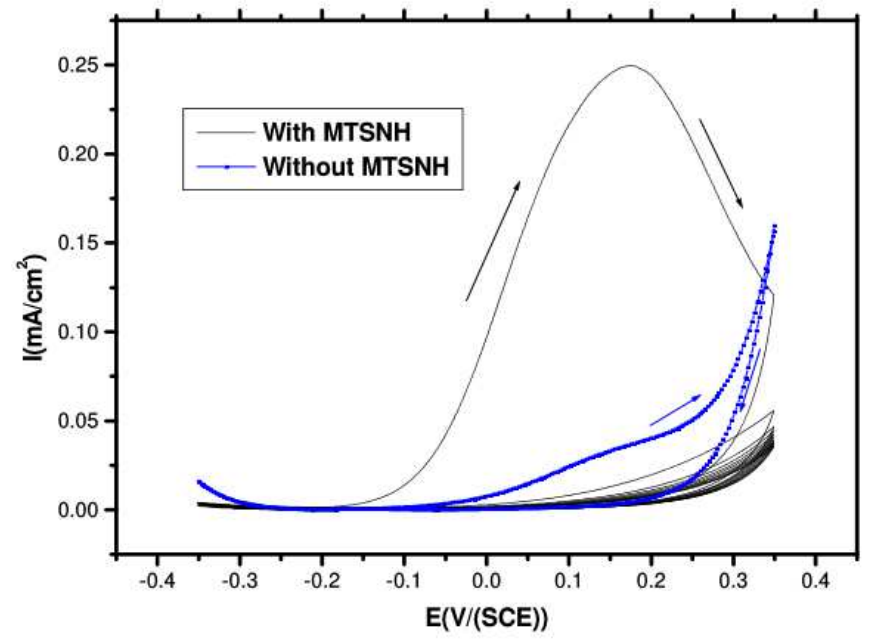

Figure 2. Voltammograms of B66 bronze substrate performed in a methanol alkaline solution at a scan rate of $10 \mathrm{mVs}^{-1}$ with $\operatorname{MTSNH}(0.001 \mathrm{M})$.

\section{Current-time curves}

To show that the chosen inhibitor is polymerized by the formation of a film onto the metal surface, we plotted the variation of the current as a function of the immersion time at different potentials, before and after the peak corresponding to the monomer oxidation. The shape of the obtained curves is shown in Fig. 3.

Fig. 3 shows a smooth current, while a thick polymer coating was formed. This improved the formation of the isolated organic layer onto the electrode surface. The low value of the current obtained at the end of the electrolysis is attributed to the oxidation of the monomer.

Current time curves show that the homogeneous and the adhesive film depend on the electrolysis potential value. At higher voltages, the fissured film is due to the oxidation of the electrolyte during the process of film formation [16]. At lower voltages, the film is formed, but this requires more time. 


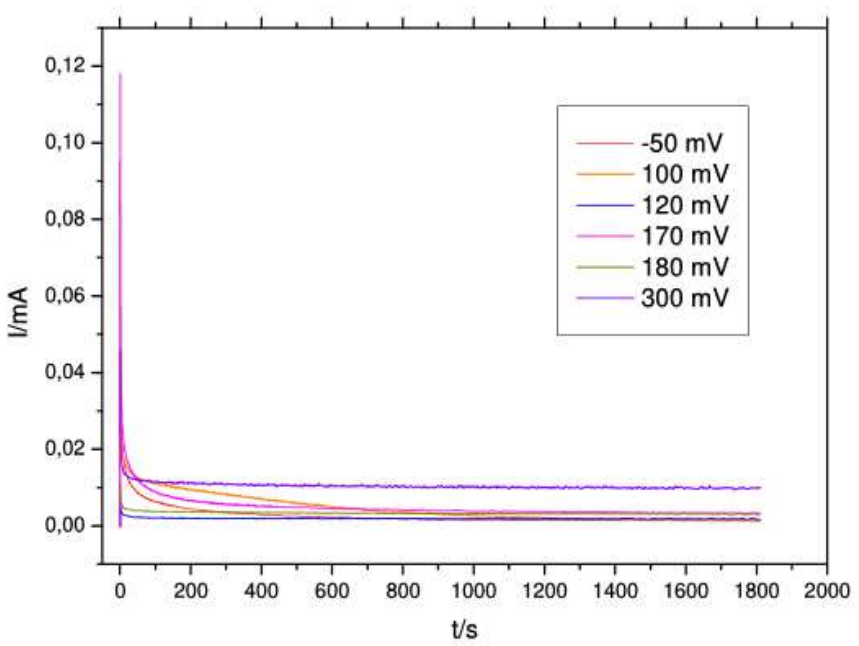

Figure 3. Current time curves of bronze electrode performed in a methanol alkaline solution at different potentials localized before and after the peak corresponding to the oxidation of the monomer.

\section{Electrochemical impedance}

The impedance diagrams shown in Fig.4 were obtained for the B66 bronze electrode at different potentials localized before and after the peak corresponding to the oxidation of the monomer in a methanol alkaline solution, at a scan rate of $10 \mathrm{mV} / \mathrm{s}$ with MTSNH $\left(10^{-3} \mathrm{M}\right)$. The obtained results are shown in Fig 4.

The polarization resistance increases with the imposed potential; it goes from 8 $\mathrm{K} \Omega . \mathrm{cm}^{-2}$ for $100 \mathrm{mV}$, to $45 \mathrm{~K} \Omega . \mathrm{cm}^{-2}$ for $176 \mathrm{mV}$ (peak of oxidation potential). This can be explained by the formation of a polymeric film by the corrosion products onto the surface of B66, which becomes more and more compact.

For potentials greater than the oxidation potential of the monomer $(E=-176$ $\mathrm{mV}$ ), the polarization resistance decreases, reflecting the cracking of the film formed onto the surface of the electrode, and the appearance of pitting.

The adjustment of these diagrams by the Ec-Lab software showed the appearance of three capacitive loops.

A high-frequency loop $\left(\mathrm{R}_{\mathrm{f}}, \mathrm{C}_{\mathrm{f}}\right)$ can be attributed to the formation of a layer on the surface of the electrode.

A second loop observed at the medium frequencies $\left(\mathrm{R}_{t}, \mathrm{C}_{\mathrm{d}}\right)$ corresponds to the charge transfer process coupled to a second mass transfer process.

Table 2. Characteristic parameters evaluated at different potentials localized before and after the peak corresponding to the oxidation of the monomer.

\begin{tabular}{|c|c|c|c|c|c|c|}
\hline Overvoltage & $\begin{array}{c}\mathbf{R}_{\mathbf{f}} \\
\left(\Omega \cdot \mathbf{c m}^{2}\right)\end{array}$ & $\begin{array}{c}\mathbf{C}_{\mathbf{f}} \\
\left(\mu \mathrm{F} . \mathrm{cm}^{2}\right)\end{array}$ & $\begin{array}{c}\mathbf{R}_{\mathbf{t}} \\
\left(\Omega . \mathbf{c m}^{2}\right)\end{array}$ & $\begin{array}{c}\mathrm{Cd} \\
\left(\mu \mathrm{F} . \mathrm{cm}^{2}\right)\end{array}$ & $\begin{array}{c}\mathbf{R}_{\mathbf{F}} \\
\left(\mathbf{\Omega . c c ^ { 2 }}\right)\end{array}$ & $\begin{array}{c}\mathrm{C}_{\mathrm{F}} \\
\left(\mu \mathrm{F} . \mathrm{cm}^{2}\right)\end{array}$ \\
\hline $100 \mathrm{mV}$ & 37.25 & 7.05 & 160 & 21.82 & 7892 & 60.07 \\
\hline $120 \mathrm{mV}$ & 57.96 & 0.61 & 17525 & 12.25 & 25555 & 42.23 \\
\hline $150 \mathrm{mV}$ & 58.53 & 0.53 & 22258 & 13.89 & 40411 & 58.96 \\
\hline $176 \mathrm{mV}$ & 57.77 & 0.49 & 21911 & 14.47 & 39980 & 50.98 \\
\hline $200 \mathrm{mV}$ & 55,24 & 0.57 & 17766 & 14.4 & 31490 & 52.70 \\
\hline
\end{tabular}

At low frequencies, we note the appearance of a third loop attributed to faradic processes $\left(R_{F}, C_{F}\right)$ which are produced at the surface of the electrode where the 
proposed inhibitor film fails. The parameters taken from these diagrams are shown in Table 2.
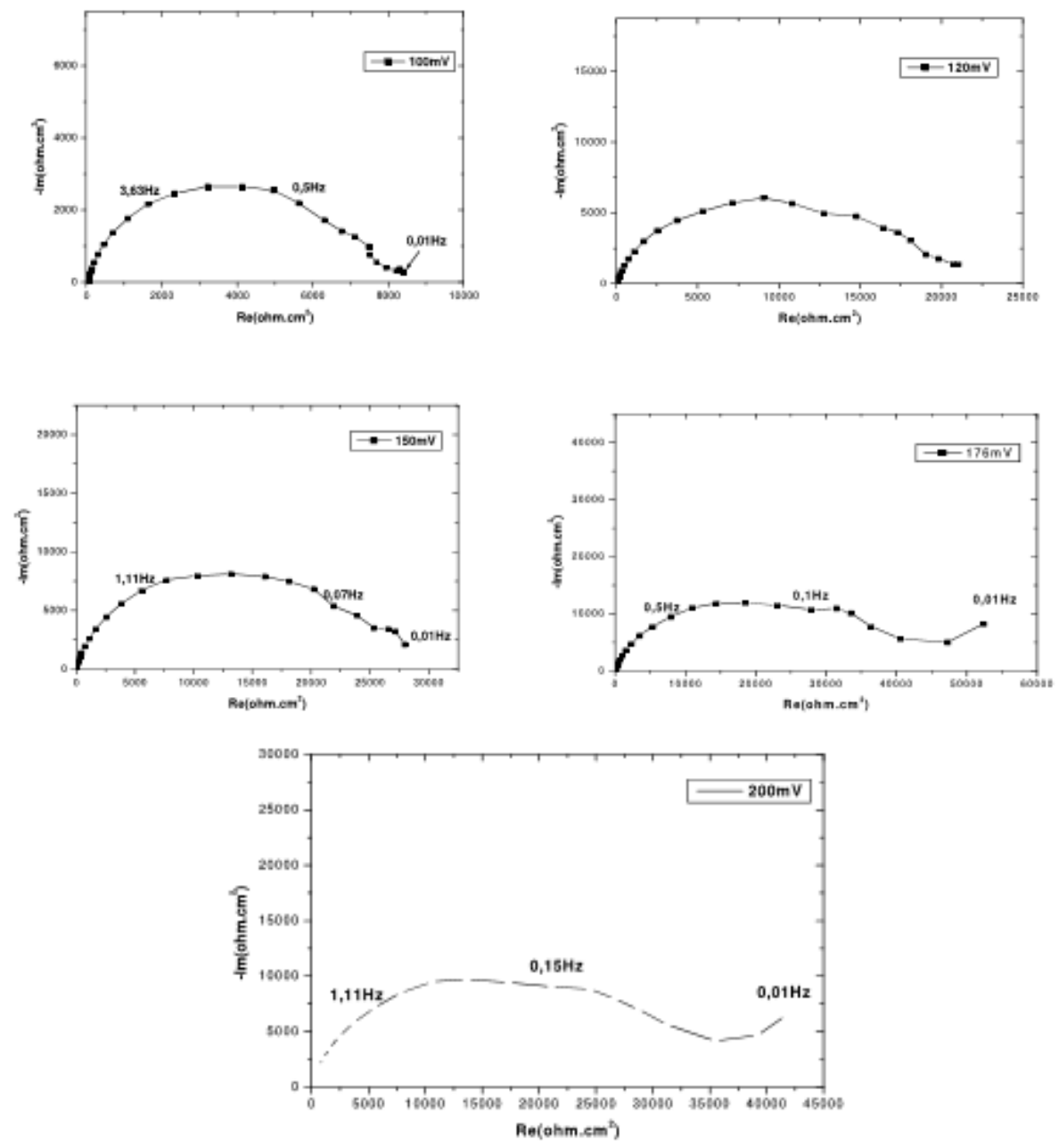

Figure 4. Electrochemical impedance diagrams obtained on bronze at different potentials localized before and after the peak corresponding to the oxidation of the monomer.

The analysis of this table shows that:

- The high frequency capacitance is very low $\left(\mathrm{C}_{\mathrm{f}}<1 \mu_{\mathrm{F}}\right)$, indicating the formation of a polymer film onto the metal surface, which is diminished when the potential increases [17]. This can be explained by the reinforcement of the formed film.

- At low frequency, the double-layer capacitance, $C_{d}$, increases with the potential; it is of the order of $14 \mu \mathrm{F}$ to $200 \mathrm{mV}$. This may be due to the decrease in the charge transfer on the metal surface.

This result could indicate a film growth which covers completely the electrode surface. 


\section{Scan rate}

Fig. 5 shows the influence of the scan rate $(5-25 \mathrm{mV} / \mathrm{s})$ on the anodic polarization curve for the electropolymerization of MTSNH from the solution containing $10^{-3} \mathrm{M}$ monomer, $10^{-1} \mathrm{M} \mathrm{KOH}$, at $298 \mathrm{~K}$, on the B66 bronze electrode.

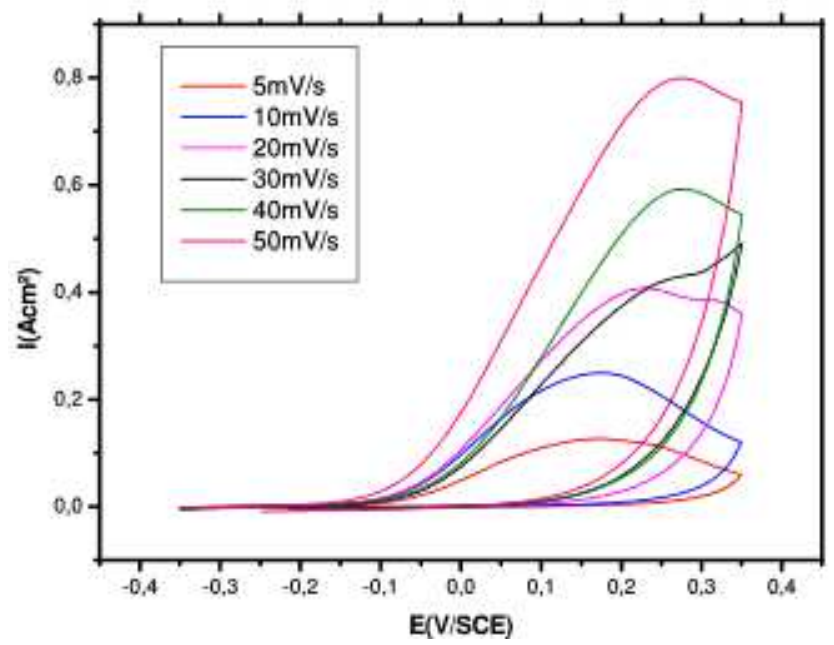

Figure 5. Cyclic voltammograms of B66 bronze in an electrodeposition medium at given scan rates, $\mathrm{mV} \cdot \mathrm{s}^{-1}$.

The data reveal that the peak current densities increase with an increase in the scan rate (Table 3).

Table 3. Effect of the scan rate on $I_{p}$ and $E_{p}$.

\begin{tabular}{|c|c|c|}
\hline Scan rate $(\mathbf{m V} / \mathbf{s})$ & $\left.\mathbf{I}_{\mathbf{p}} \mathbf{( m A . c m}^{-\mathbf{2}}\right)$ & $\mathbf{E}_{\mathbf{p}}(\mathbf{m V})$ \\
\hline $\mathbf{5}$ & 0.129 & 173 \\
\hline $\mathbf{1 0}$ & 0.249 & 176 \\
\hline $\mathbf{2 0}$ & 0.411 & 230 \\
\hline $\mathbf{3 0}$ & 0.426 & 263 \\
\hline $\mathbf{4 0}$ & 0.592 & 273 \\
\hline $\mathbf{5 0}$ & 0.799 & 278 \\
\hline
\end{tabular}

This behavior may be explained as follows: when enough potential is applied at an electrode surface, causing oxidation of species in the solution, a current arises due to the depletion of the species in the vicinity of the electrode surface. The current $\left(i_{p}\right)$ is proportional to the gradient slope. As the scan rate increases, the gradient increases also and, consequently, the current $\left(i_{p}\right)$ values are directly proportional to $\mathrm{v}^{1 / 2}$, according to the Sevcik and Randles equation [18]:

$$
\mathrm{I}_{\mathrm{p}}=0.4463 \mathrm{nFAC}(\mathrm{nFvD} / \mathrm{RT})^{1 / 2}
$$

where $I_{p}$ is the peak current, $n$ is the number of electrons, $F$ is the Faraday constant, $\mathrm{T}$ is the temperature in Kelvin, $\mathrm{R}$ is the gas constant, $\mathrm{A}$ is the surface area of the working electrode, $\mathrm{D}$ is the diffusion coefficient of the electroactive species, $\mathrm{C}$ is the bulk concentration of the electroactive species and $\mathrm{v}$ is the scan rate of voltammograms. 


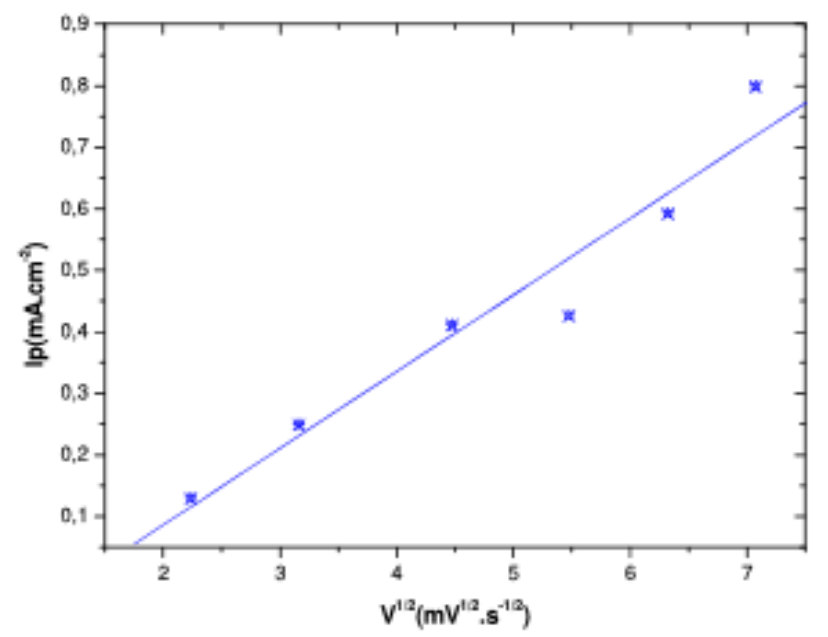

Figure 6. Linear dependence of $\mathrm{Ip}$ on $\mathrm{v}^{1 / 2}$ for B66 bronze in an electrodeposition medium.

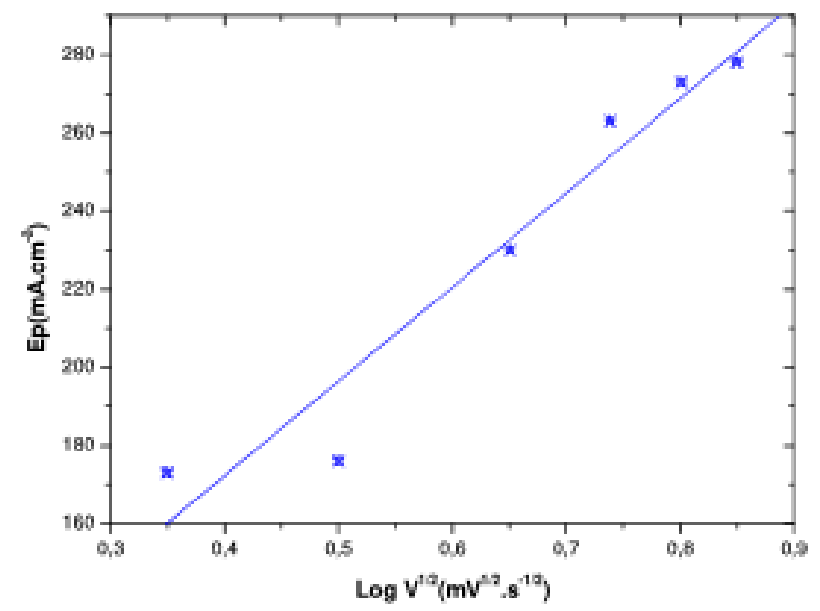

Figure 7. Linear dependence of $E_{p}$ on $\log \left(v^{1 / 2}\right)$ for $B 66$ bronze in an electrodeposition medium.

Fig. 6 shows the linear dependence of the peak, $\left(I_{p}\right)$, versus $v^{1 / 2}$. This linear regression equation was $\mathrm{I}_{\mathrm{p}}(\mathrm{mA})=0.124 \mathrm{v}^{1 / 2}-0.16$, with a correlation coefficient of $r^{2}=0.97$. So, we suggest that the electroformation of the radical cation may be described by a diffusion-controlled process [19].

Additionally, it is also found that the $E_{p}$ value of the peak shows a linear variation with the logarithmic scan rate (Fig.7). These findings suggest that the anodic process, in the monomer oxidation potential range, is under diffusion control, and that the corresponding system is completely irreversible [20].

\section{Effect of temperature}

The potentiodynamic polarization curves as a function of the solution temperatures in the range from 303 and $318 \mathrm{~K}$, under the same experimental conditions as mentioned above, are illustrated in Fig. 8. 


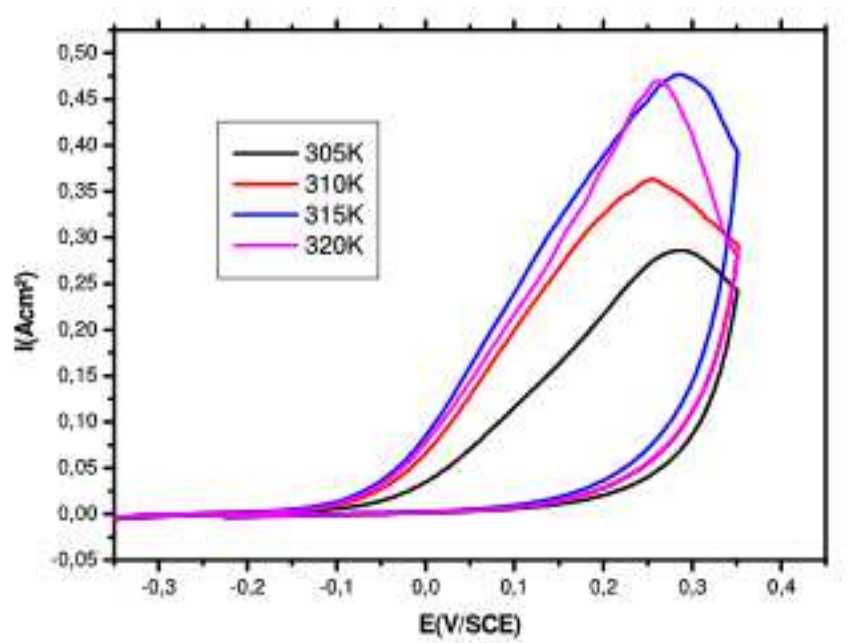

Figure 8. Cyclic voltammogram curves for the effect of temperature on the electropolymerization of MTSNH from a solution containing $10^{-3} \mathrm{M}$ of monomer with a scan rate of $10 \mathrm{mV} / \mathrm{s}$.

From this figure, it is clear that an increase of temperature up to $313 \mathrm{~K}$ results in a progressive increase of the charge included in the anodic peak (Table 4). The plot of the $\log \left(i_{\text {pI }}\right)$ versus $1 / \mathrm{T}$ is represented in Fig. 9, where a straight line is obtained with a slope equal to -29.16 , and then the apparent activation energy $\left(\mathrm{E}_{\mathrm{a}}\right)$ was calculated using Arrhenius equation, and it was found to be 242.43 $\mathrm{KJ} / \mathrm{mol}$.

Table 4. Effect of temperature on $\mathrm{I}_{\mathrm{p}}$ and $\mathrm{E}_{\mathrm{p}}$.

\begin{tabular}{|c|c|c|}
\hline $\mathbf{T}(\mathrm{K})$ & $I_{p}\left(\mathrm{~mA} . \mathrm{cm}^{-2}\right)$ & $\mathrm{E}_{\mathrm{p}}(\mathrm{mV})$ \\
\hline 298 & 0.248 & 176 \\
\hline 303 & 0.288 & 289 \\
\hline 308 & 0.262 & 255 \\
\hline 313 & 0.478 & 282 \\
\hline 318 & 0.471 & 261 \\
\hline
\end{tabular}

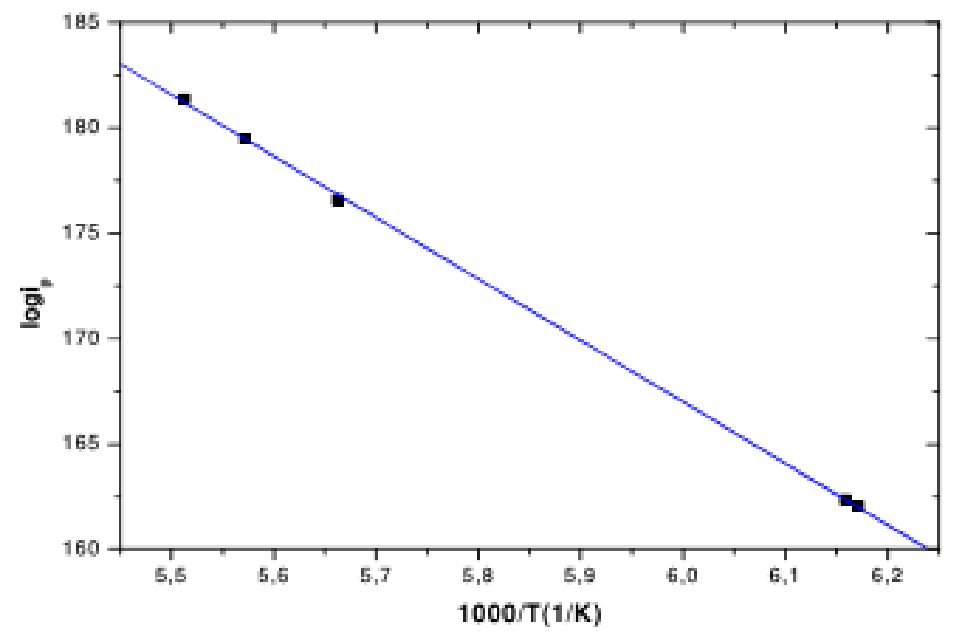

Figure 9. Arrhenius plot of the electropolymerization of MTSNH to a radical cation. 
Evaluation of the corrosion resistance of poly (MTSNH) films in 3.5\% sodium chloride solutions

Polarization curves

The cathodic and anodic polarizations curves obtained after one hour of immersion at the corrosion potential in 3.5\% solutions, with the corrosion potential stabilizing, without and with a polymeric film, are shown in Fig.10.
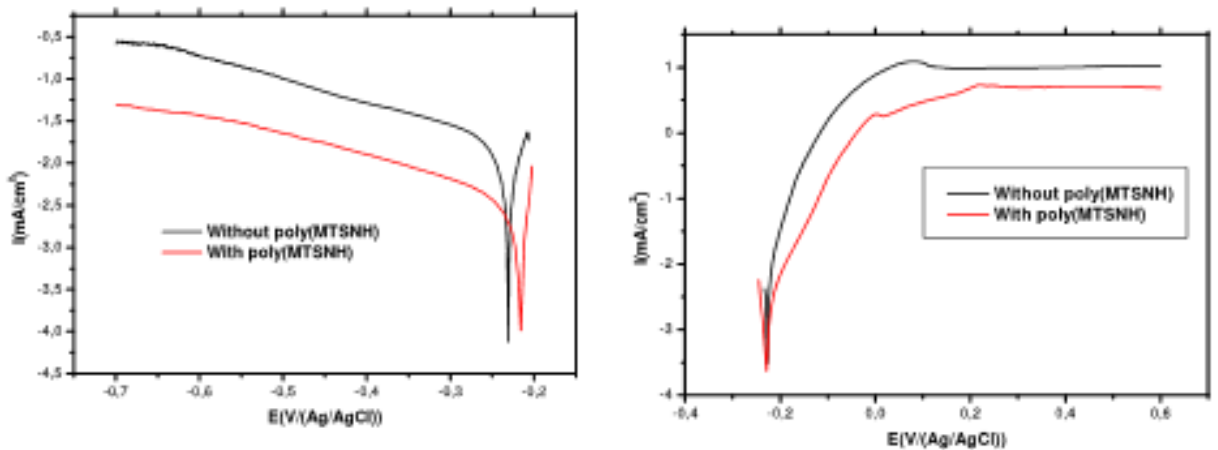

Figure 10. Cathodic and anodic current-voltage curves of B66 bronze in an aerated $3.5 \% \mathrm{NaCl}$ solution, with and without poly (MTSNH).

It is clear from Fig.10 that the presence of poly (MTSNH) on the electrode surface decreases at the cathodic current densities in the vicinity of the corrosion potential, with its slight shift towards positive values, which is attributed to the formation of the insulating film. On the other hand, in the anodic domain, a slight decrease of the anodic current is observed in the presence of a polymeric film.

The results depicted in Table 5 show a decrease in the corrosion current density in the presence of the polymeric film; the inhibiting efficiency is $92.5 \%$, indicating an excellent protective effect of poly (MTSNH).

Table 5. Electrochemical parameters of $\mathrm{B} 66$ bronze in a $3.5 \% \mathrm{NaCl}$ solution, without and with polymeric film.

\begin{tabular}{|c|c|c|c|c|}
\hline & $\begin{array}{c}\mathbf{E}_{\text {corr }} \\
(\mathbf{m V})\end{array}$ & $\begin{array}{c}\mathbf{I}_{\mathbf{c o r r}} \\
\left(\boldsymbol{\mu} \mathbf{A . c m}^{-2}\right)\end{array}$ & $\begin{array}{c}\mathbf{b}_{\mathbf{C}} \\
(\mathbf{m V})\end{array}$ & $\mathbf{E} \%$ \\
\hline Without & -228 & 8.04 & -11 & -- \\
\hline With poly(MTSNH) & -215.16 & 0.6 & -30.2 & 92.5 \\
\hline
\end{tabular}

\section{Electrochemical impedance measurements}

Fig.11 presents the evolution of impedance spectra in $3.5 \% \mathrm{NaCl}$ at $\mathrm{E}_{\text {corr }}$, in the presence and absence of a polymeric film.

In the absence of the inhibitor, the Nyquist diagram of impedance presents a flattened semi-circle with a deformation in the high frequency domain. The polarization resistance determined from the extrapolation of the impedance spectra is about $1167 \Omega \mathrm{cm}^{2}$. Assuming that this impedance data can be described by two $\mathrm{R}$ and $\mathrm{C}$ ladder circuits, the impedance spectrum could be fitted suitably [21].

As a matter of fact, the results obtained by a non-linear regression calculation are close to the experimental data. 
In the presence of the polymer, there is a capacitive behavior of the alloy in a $\mathrm{NaCl}$ medium (Fig. 11).

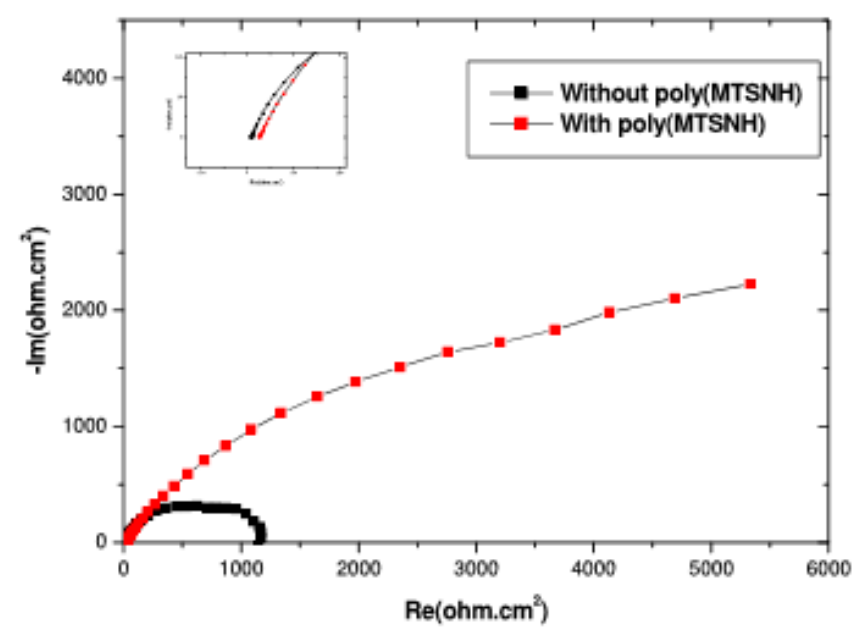

Figure 11. Electrochemical impedance diagrams of B66 bronze, without and with poly (MTSNH) coating in a $3.5 \% \mathrm{NaCl}$ solution.

The polarization resistance, $R_{p}$, determined from the extrapolation of the impedance spectra towards the low frequency limit increases in the presence of the polymer. $R_{p}$ is about $1.167 \mathrm{~K} \Omega \mathrm{cm}^{2}$ in a $3.5 \% \mathrm{NaCl}$ solution without polymer, whereas it reaches $8 \mathrm{k} \Omega \mathrm{cm}^{2}$ with poly (MTSNH).

However, these diagrams cannot be explained with only two $\mathrm{R}$ and $\mathrm{C}$ circuits, and thus, a third $\mathrm{R}-\mathrm{C}$ circuit was added. The use of such an electrical equivalent circuit is in agreement with the previous results presented and discussed in the references [22, 23]. Those $\mathrm{R}-\mathrm{C}$ couples are ascribed to the following contributions: the high frequency contribution $\left(\mathrm{C}_{\mathrm{f}}-\mathrm{R}_{\mathrm{f}}\right)$ is ascribed to the dielectric character of the f corrosion products $\left(\mathrm{C}_{\mathrm{f}}\right)$ which reinforced the formed film.

The medium frequency contribution is attributed to the double layer capacitance $\left(\mathrm{C}_{\mathrm{d}}\right)$ at the electrolyte/bronze interface, coupled with the charge transfer resistance $(\mathrm{R})$, whereas the low frequency elements are related to the oxidationreduction contribution of the corrosion products $\left(\mathrm{R}_{\mathrm{F}}-\mathrm{C}_{\mathrm{F}}\right)$.

The values determined from a non-linear regression calculation for couples $\left(\mathrm{C}_{\mathrm{f}}-\mathrm{R}_{\mathrm{f}}\right),\left(\mathrm{C}_{\mathrm{d}}-\mathrm{R}_{\mathrm{t}}\right)\left(\mathrm{C}_{\mathrm{F}}-\mathrm{R}_{\mathrm{F}}\right)$ are summarized in Table 6.

Table 6. Effect of B66 bronze electrode immersion time on characteristic parameters evaluated in high and low frequency ranges.

\begin{tabular}{|c|c|c|c|c|c|c|c|}
\hline & $\begin{array}{c}\mathbf{R}_{\mathbf{f}} \\
\left(\mathbf{\Omega . c m}^{2}\right)\end{array}$ & $\begin{array}{c}\mathbf{C}_{\mathbf{f}} \\
\left(\boldsymbol{\mu} \mathbf{F c m}^{-2}\right)\end{array}$ & $\begin{array}{c}\mathbf{R}_{\mathbf{t}} \\
\left(\mathbf{K \Omega . c m}^{2}\right)\end{array}$ & $\begin{array}{c}\mathbf{C}_{\mathbf{t}} \\
\left(\boldsymbol{\mu} \mathbf{F c m}^{-2}\right)\end{array}$ & $\begin{array}{c}\mathbf{R}_{\mathbf{F}} \\
\left(\mathbf{K}_{\mathbf{2 . c m}}\right)\end{array}$ & $\begin{array}{c}\mathbf{C}_{\mathbf{F}} \\
\left(\mathbf{m F c m}^{-2}\right)\end{array}$ & $\begin{array}{c}\mathbf{E} \\
(\boldsymbol{\%})\end{array}$ \\
\hline $\begin{array}{c}\text { Without } \\
\text { poly } \\
(\mathbf{M T S N H})\end{array}$ & $\ldots$ & $\ldots$ & 0.853 & 170 & 1.167 & 1.90 & $\ldots$ \\
\hline $\begin{array}{c}\text { With } \\
\text { poly } \\
\text { (MTSNH) }\end{array}$ & 943.2 & 9.627 & 4.676 & 130 & 8 & 20.44 & 85 \\
\hline
\end{tabular}


The examination of this table shows that, in the presence of the polymer, the polarization resistance value at low frequency increases in the presence of the polymer, whereas the capacity value decreased from $170 \mu \mathrm{F}_{\mathrm{cm}}{ }^{-2}$ to $130 \mu \mathrm{F} . \mathrm{cm}^{-2}$. The increase in the $R_{p}$ value noted in Fig. 11 means that the polymer film formed by electropolymerization of MTSNH onto the metal surface is protective.

\section{Suggested mechanism of poly (MTSNH) formation}

Considering the monomer structure, we suggest one process of electropolymerization of the 4-amino-3-methyl-1,2,4-triazole-5-thione on the metallic substrate, according to the reaction pathway (Fig. 12).

\section{Surface analysis}

The surface analysis was examined by SEM/EDS of B66 bronze, in the absence and presence of poly (MTSNH).

Fig. 13(a) and 13(b) show the SEM micrographs coupled with EDS spectra for B66 bronze, without and with polymer, respectively.
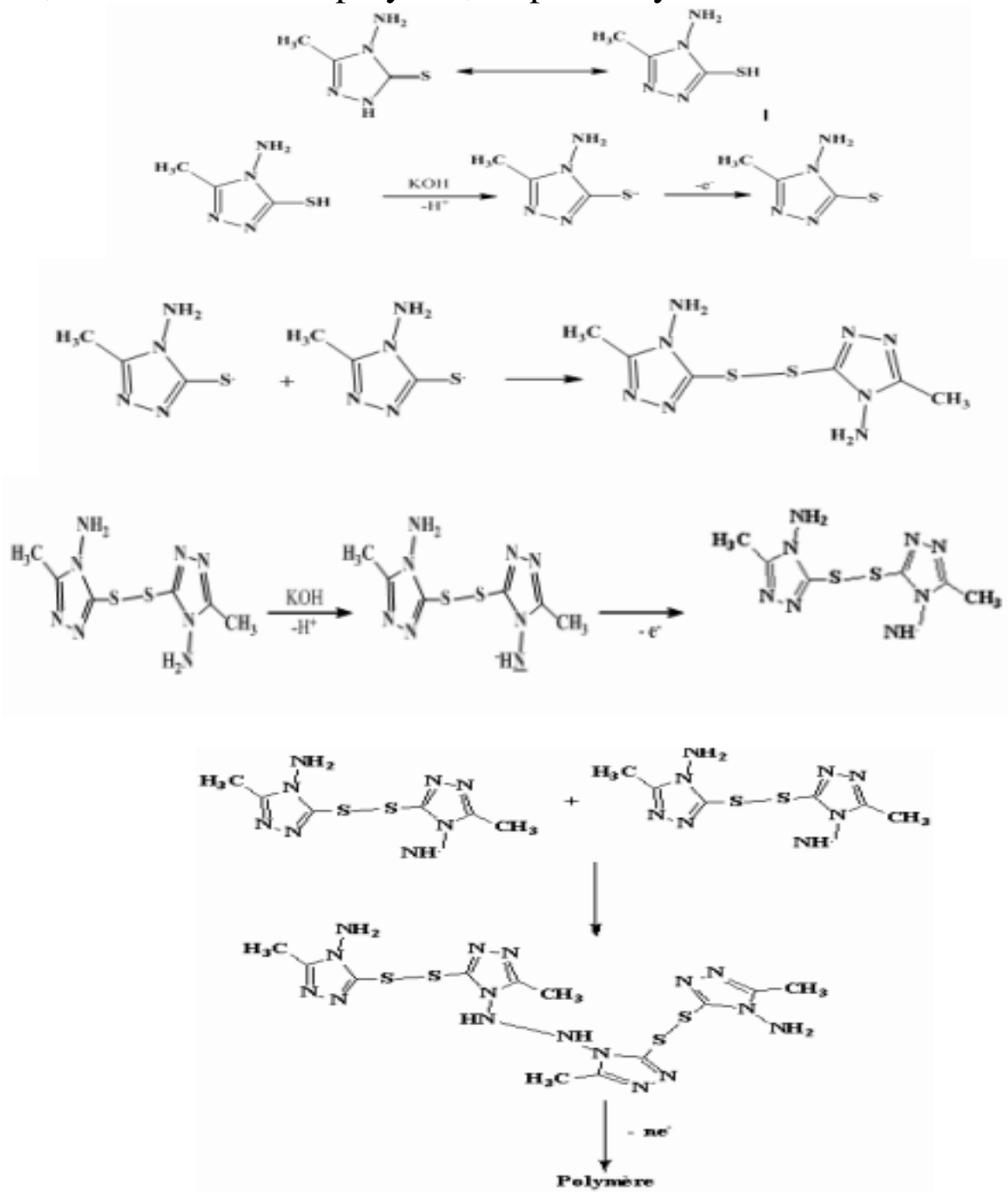

Figure 12. Suggested mechanism of poly (MTSNH) formation.

The EDS spectra show that, in the presence of the poly (MTSNH), the appearance of elements such as $\mathrm{S}, \mathrm{C}$, and $\mathrm{N}$ indicates the presence of the polymer 
onto the bronze surface, whereas in the absence of the polymer, the EDS spectra show the characteristic peaks of the elements from the bronze alloy (copper and lead), along with carbon and oxygen from contamination.

This study proves distinctly the formation of the polymer onto the bronze surface.

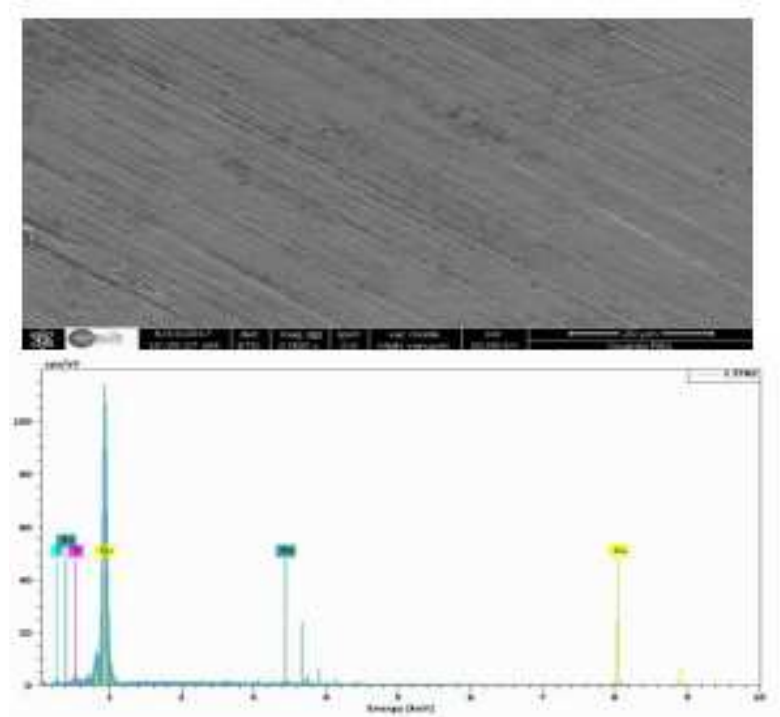

Figure 13(a). SEM image and EDX spectrum of B66 bronze without polymer.

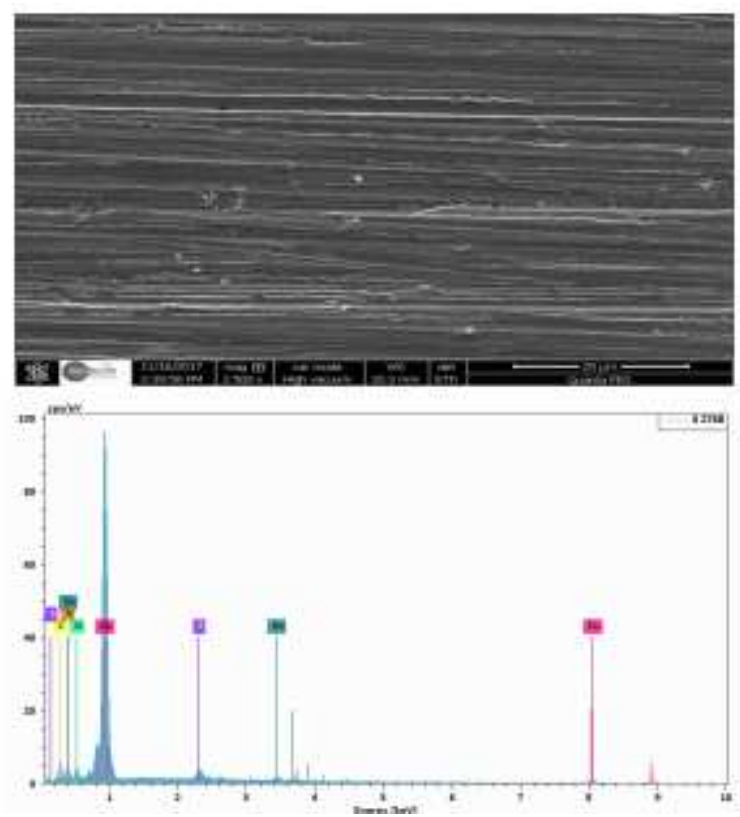

Figure 13(b). SEM image and EDX spectrum of B66 bronze with polymer.

\section{Conclusions}

In conclusion, the above data of 4-amino-3-methyl-1,2,4-triazole-5-thione oxidation in methanol, in the presence of $\mathrm{KOH}$, reveal the following:

1- From cyclic voltammetry studies, it is clear that the cyclic voltammogram consists of one irreversible anodic peak at $176 \mathrm{mV}$.

2- The electropolymerization of the monomer gives an insulating polymer. 
3- The electrodepositing process of the polymer film on the bronze electrode may be described partially by a diffusion-controlled step.

4- Heat-treatment of the polymer improves its homogeneity and adherence to the bronze electrode on which it is formed.

5- The protective effect of the film formed on B66 bronze has been studied in $3.5 \% \mathrm{NaCl}$.

6- A mechanism for the formation of the poly-MTSNH is proposed considering a radical reaction.

\section{References}

1. Assouli B, Ait Chikh ZA, Idrissi H, et al. Polymer. 2001;43:2449-2454.

2. Fukuhara T, Akıyama Y, Yoneda N, et al. J Tetrahedron Lett. 2002;43:6583.

3. Matsushita M, Kuramitz H, Tanaka S. J Environ Sci Technol. 2005;39:3805.

4. Cao H, Huang Y, Sun J. J Comp Sci Tech. 2005;65:1655.

5. Sarac AS, Bardavit Y. J Prog Org Coat. 2004;49:85.

6. Hua S, Brisena AL, Shi X, et al. J Phys Chem B. 2002;106:6465.

7. Kumru EM, Springer J, Saraç AS, et al. J Synth Met. 2001;123:391.

8. El Rehim SSA, Sayyah SM, Azooz RE. Port Electrochim Acta. 2012;30-1:67-80.

9. Sayyah SM, Abd El-Rehim SS, El-Deeb MM, et al. J Appl Polym Sci. 2011;119: 252-264.

10. ELbakri M, Touir R, Ebn Touhami M, et al. Corros Sci. 2008;50:1538-1545.

11. Rahmouni K, Keddam M, Srhiri A, et al. Corros Sci. 2005;47:3249-3266.

12. Chebabe D, Dermaj A, Erramli H, et al. Anti-Corrosion Meth Mater. 2014;61:281-286.

13. Boukamp BA. Equivalent Circuit. Princeton: Princeton Appl Res Co; 1990.

14. Amin MA. Weight loss, polarization, electrochemical impedance spectroscopy, SEM and EDS studies of the corrosion inhibition of copper in aerated $\mathrm{NaCl}$ solutions. J Appl Electrochem. 2006;36:215.

15. Rohom AB, Londhe PU, Mahapatra SK, et al. High Perf Polym. 2014;26:641-646.

16. Perrin FX, Pagetti J. Electrochem Meth Corros Res. IV. 1998;440-446.

17. Ait Chikh Z. Doctoral Dissertation, Ibn Tofail University, Kenitra, Morocco. 2001.

18. Neghmouche NS, Lanez T. Int Lett Chem Phy Ast. 2013;76-85.

19. Mazloum-Ardakani M, Sadeghiane A, Moosavizadeh S, et al. Anal Bioanal Electrochem. 2009;1:224-338.

20. Bard A, Faulkner LR. Electrochimie methodes. Paris: Editions Masson; 1983.

21. Benassaoui H, Dermaj A, Chebabe D, et al. Organic Chemistry An Indian Journal. 2015;11(12):433-441.

22. Trachli B, Co-tutelle Doctoral Dissertation, P\&M Curie University (France), Ibn Tofail University, Morocco. 2001.

23. Dermaj A, Hajjaji N, Joiret S, et al. Electrochim Acta. 2007:52:4654-4662. 